\title{
All different or all the same? Exploring the diversity of professional practices in Portuguese school psychology
}

\author{
Sofia A. Mendes ${ }^{1}$ • Jon Lasser ${ }^{2}$. \\ Isabel M. P. Abreu-Lima ${ }^{1} \cdot$ Leandro S. Almeida $^{3}$
}

Received: 16 September 2015 /Revised: 27 February 2016/Accepted: 2 March 2016

(C) Instituto Superior de Psicologia Aplicada, Lisboa, Portugal and Springer Science+Business Media Dordrecht 2016

\begin{abstract}
Studies have generally characterized school psychologists as a relative homogenous population. Understanding the differences in professional practices and related variables is important for the development of the profession. Using a sample of 446 Portuguese school psychologists, this study used cluster analysis to identify distinct profiles of professional activity, based on practitioners' time distribution among different target audiences (i.e., students, parents, teachers, school board members, school non-professional staff, and other professionals within the school community). Three distinct profiles emerged from the data: a group highly oriented to work with students, a group that distributes time almost equitably between adults and students, and a group that concentrates attention and professional expertise on adults. Practice setting variables, such as school-psychologists-to-student ratio, schoolpsychologists-to-school ratio, number of referrals per year, and school community level of demand for different activities, were found to be significantly related to cluster membership. No personal- or professional-background-related variables differentiated the three groups. The main implications of these findings are discussed in light of recent literature regarding the models of service delivery for school psychologists.
\end{abstract}

Keywords School psychology Professional practice $\cdot$ Cluster analysis

Survey research has a long tradition in the field of school psychology and has been widely used to collect data and answer research questions about school psychologists, their attitudes, and responsibilities. Several authors have stressed the importance of systematically gathering

Sofia A. Mendes

sofia.a.mendes@gmail.com

1 University of Porto, Porto, Portugal

2 State Texas University, San Marcos, USA

3 University of Minho, Braga, Portugal 
this sort of information in order to advance the knowledge and practice of school psychology (e.g., Bramlett et al. 2002; Jimerson et al., 2004; Reschly \& Wilson, 1995; Oakland \& Cunningham, 1992). Beyond the purpose of informing practitioners, trainers, and researchers, data collected from school psychologists can be used to advocate for the profession within the public, public policy, education, and mental health circles.

Scholars in the USA have been at the forefront of this line of research, with the National Association of School Psychologists (NASP) periodically surveying or supporting surveys of its members since 1989 (Castillo et al. 2012). One of the primary goals of these surveys has been to describe school psychologists' work time distribution across different functions and roles. The inconsistent categorization of school psychologists' practices requires caution when interpreting and comparing results across surveys. For example, some researchers have divided the practices of school psychologists into five categories, including assessment, counseling, problem-solving consultation, systems consultation, and research (e.g., Hosp \& Reschly, 2002; Reschly \& Wilson, 1995). Others have divided practices more discreetly, distinguishing different activities related to assessment, types of counseling, and consultation practices, or considering further service delivery categories (e.g., conferencing, supervision, and in-service training) (e.g., Bramlett et al., 2002; Lacayo et al. 1981; Smith, 1984).

Nevertheless, state and national surveys have repeatedly reported that school psychologists spend about half of their time in assessment activities (e.g., Benson \& Hughes, 1985; Bramlett et al., 2002; Hosp \& Reschly, 2002; Lacayo et al. 1981; Reschly \& Wilson, 1995; Smith, 1984; Stinnett et al. 1994) and more than two thirds in services related to special education (e.g., Castillo et al., 2012; Curtis et al., 2008). Contrariwise, research has generally found that school psychologists only spend between 16 and $25 \%$ of their time in consultation, 8 and $25 \%$ in intervention, and 1 and $2 \%$ in research (e.g., Benson \& Hughes, 1985; Bramlett et al., 2002; Hosp \& Reschly, 2002; Lacayo et al., 1981; Reschly \& Wilson, 1995; Stinnett et al., 1994).

Another important set of studies has focused on the development of school psychology internationally. A variety of titles including psychologist, school psychologist, educational psychologist, counselor, or psychopedagogue are used worldwide to designate those professionals providing psychological services in educational setting (Jimerson et al. 2008a, b). To facilitate international communication, the term school psychologist is commonly used and was adopted through this article.

The International School Psychology Survey (ISPS) represents the most recent source of empirical evidence about the status of school psychology around the world, gathering information from about 800 school psychologists of 16 countries across Europe, Africa, Asia, and Australia (Jimerson et al. 2007, 2008a, b, 2009, 2010). In most countries surveyed with ISPS, psychoeducational evaluation and counseling have emerged as the most time-consuming professional practices (e.g., Albania, Australia, Egypt, Estonia, Germany, Italy, North England, Russia, Switzerland, United Arab Emirates, and USA). If adding up the total time spent on consultation with school staff, parents, and families, one can observe that in the majority of countries inquired, one quarter or more of school psychologists' time was also dedicated to consultation (e.g., Albania, Australia, China, Cyprus, Germany, Greece, Italy, North England, USA, and New Zealand). In contrast, a small percentage of practitioners' time was spent in activities such as primary prevention, staff training, and in-service education (Jimerson et al. 2007, 2008a, b, 2009, 2010).

The ISPS findings also suggest that, throughout the world, there appears to be little consensus about a model of practice for practitioners, revealing a lack of agreement regarding 
the ideal roles of school psychologists. Despite these differences in theoretical positions, in almost all countries surveyed, school psychologists identified assessment, counseling, consultation, and primary prevention as the top four ideal roles. On the other hand, respondents almost unanimously rated administrative responsibilities as the least optimal role (Jimerson et al. 2007, 2008a, b, 2009, 2010).

The information from a 2012 survey revealed that school psychologists in Portugal spend on average $56 \%$ of their time working directly with students, mainly from the 7 th to 12 th grade. Within this survey, school psychologists reported devoting $20 \%$ of their time to counseling, $19 \%$ to psychoeducational evaluation, $18 \%$ to vocational guidance, $13 \%$ to special education, $11 \%$ to promotion and prevention, $9 \%$ to school staff training and consultation, $6 \%$ to parents/family training and consultation, $4 \%$ to community liaison, and $1 \%$ to research. This pattern of activity points to a professional practice still tied to traditional roles, primarily focused on psychologist-child interaction and remediation activities (Mendes et al. 2014). This model of practice, commonly designated as the medical model, still prevails within the profession, similar to that occurs in other countries. For more details about the history and status of school psychology in Portugal, please see (Mendes et al., 2014; Mendes et al. 2015).

Historically, like other subspecialties within psychology, school psychology has demonstrated overreliance on the medical model to conceptualize and address school and mental health problems (Gutkin \& Song, 2013). Within this approach, educational and psychological difficulties are understood in terms of learners' individual deficits, without equal consideration being given to important environmental factors (Williams \& Greenleaf, 2012). It is also assumed that the diagnosis of educational problems precedes treatment or service provision (Merrell et al. 2012), which can only be identified by carrying out the appropriate tests, whose results tend to be accepted without question and used to foresee future outcomes (Farrell, 2006).

Traditionally, deficit theories have guided special education policies and influenced the practice of school psychologists, resulting in a service delivery model centered on students that emphasizes assessment, diagnosis, and treatment techniques (Bartolo, 2010; Christner et al. 2011; Engelbrecht, 2004; Farrell, 2010; Gutkin \& Conoley, 1990; Sheridan \& Gutkin, 2000). In this paradigm, school psychologists are routinely called to diagnose and repair those students who do not fit into the regular education (Braden et al. 2001; Merrell et al., 2012; Murray, 1996; Strein et al. 2003). Accordingly, school psychologists assess the referred child, establish a diagnosis, and design and implement a treatment plan, commonly through counseling, therapy, or other form of direct interventions (Sheridan \& Gutkin, 2000; Williams \& Greenleaf, 2012).

Presently, there is a vast literature that represents a long-standing movement against the medical model of service delivery (e.g., Bartolo, 2010; Braden et al., 2001; Burns, 2011; Engelbrecht, 2004; Farrell, 2006, 2010; Gutkin \& Conoley, 1990; Gutkin, 2012; Reschly, 2004; Sheridan \& Gutkin, 2000; Williams \& Greenleaf, 2012). There is a general agreement that school psychologists should move toward a more comprehensive system of services that emphasizes the role of key social contexts (e.g., home, school, and community) and socializing agents (e.g., peers, parents, teacher, and other professionals) in the development and psychological adjustment of individuals (Nastasi, 2000). This perspective redirects school psychologist to address children's problems by working with their teachers, parents, and other caregivers, to act as a link between systems and as a coordinator and facilitator of interventions and teamwork (Burns, 2011; Engelbrecht, 2004; Nastasi, 2000, 2004; Sheridan \& Gutkin, 2000). 
This conceptualization of school psychology as primarily an indirect service has represented a major advance in the understanding of what constitutes effective professional practices (Strein et al., 2003). Nonetheless, school psychologists have been recently called to adopt a public health perspective within their practice (Cummings et al., 2004; Doll \& Cummings, 2007; Ehrhardt-Padgett et al. 2004; Gutkin \& Song, 2013; Gutkin, 2012; Nastasi, 2004; Strein et al., 2003; Ysseldyke et al., 2006). Within this framework, school psychologists are expected to provide a comprehensive continuum of services that range from prevention and early intervention to treatment (Meyers \& Swerdlik, 2003; Nastasi, 2000, 2004). This multilevel approach is intended to meet the needs of the entire school community by matching the level of support to the nature and severity of students' problems (Ysseldyke et al., 2006). It also directs school psychologist to spend more time and resources in interventions targeting the entire student body and those students at risk (i.e., universal and targeted interventions) and less time on assessment and interventions aimed to remediate individuals or groups (i.e., intensive interventions) (Strein et al., 2003). This model of service delivery is conceived as being more efficient and cost-effective (Burns, 2011).

All these ideas are reflected in the NASP Model for Comprehensive and Integrated School Psychological Services (NASP, 2010), a model intended to guide the delivery of school broadbased psychological services. Within this framework, school psychology services are described in a continuum: direct-indirect services and student-systems levels services. This continuum is defined by the extent that services require face-to-face contact with students or are delivered through a third party (e.g., parents, teachers, or other professionals). It is also defined by the degree to which services focus on students' individual concerns or on systemic variables.

This conceptualization of service delivery is linked to a central topic of discussion within the profession, the definition of school psychologists' primary target audiences. Gutkin and Conoley (1990) were the first to conceive school psychology as an indirect service profession and to reflect about the advantages and disadvantages of a child- versus adult-centered practice. However, contemporary perspectives on service delivery support a balanced and integrated combination of direct and indirect services as the best way to address the needs of the students (e.g., NASP, 2010).

Despite all the recommendations and criticism around school psychologists' roles, which are well known among practitioners (Farrell, 2006), the discrepancy between the actual and potential role of school psychologists tends to persist (Merrell et al., 2012). Several factors have been recognized as affecting how school psychologists distribute their time and as perpetuating this conflict between actual and potential roles. Fagan and Wise (2007) conceptually organized these factors in three groups, including what the person brings to the job, the job site characteristics, and external variables. However, the authors do not empirically support the discussion of these factors.

Limited empirical published research has in fact examined the factors that influence school psychologists' roles. Of the few studies existing, most focus on personal and contextual-related variables, such as practitioners' training, professional background, and school-psychologiststo-student ratios (e.g., Brown et al. 1998; Costenbader et al. 1992; Curtis et al. 2002; Hosp \& Reschly, 2002; Hughes \& Clark, 1981). One common limitation of these studies is their inability to produce strong and consistent findings. Other studies have also supported the influence of school staffs' attitudes and perceptions toward the profession on school psychologists' roles (e.g., Farrell et al. 2005; Gilman \& Gabriel, 2004; Gilman \& Medway, 2007; Kikas, 1999; Magi \& Kikas, 2009; Watkins et al., 2001). These last factors in particular, along 
with practitioners-to-student ratios, have been identified favoring the maintenance of direct services at the individual level.

Survey research has generally drawn an overall picture of school psychologists and their services by using descriptive analysis. To date, no peer-reviewed articles have sought to distinguish and describe school psychologists according to distinct patterns of activity. Examining professional practices in a more integrated and comprehensive manner is consistent with current perspectives on service delivery (e.g., NASP, 2010). It also can contribute to a more accurate and deeper understanding of the status of the profession, namely, the extent to which practitioners are in line with recommended practices. As critical is to identify the factors that directly influence professional roles and role change in order to develop strategic goals and action plans that target these variables (Curtis et al., 2002). This information is relevant to influence and guide policymakers, legislator, and other stakeholders whose positions and actions can contribute to guarantee that all students receive optimal psychological services in schools.

Summarizing, this study addresses two research questions. First, what patterns of professional practice can be found among Portuguese school psychologists? Second, what factors can help us to understand different patterns of service delivery? In this study, distinct profiles of professional practice were explored considering practitioners' time spent with different target audiences. This option is consistent with an ecologic perspective of school psychology services.

\section{Method}

\section{Participants}

The data for this research came from a nationwide online survey, which details can be found in Mendes et al. (2014). For this study, a sample of 446 practicing school psychologists was considered. Participants were mainly female (88 \%) and reported an average age of 39 years $(S D=8.30)$ and 12 years of experience as a school psychologist $(S D=7.40)$. Most of the participants reported to hold a licentiate degree in psychology (63\%), equivalent to four to five of higher education studies. About half of the sample had received their highest degree in domains such as school, educational, developmental, or vocational psychology (45\%). Most participants worked in public schools (82\%), typically located in urban settings (46\%), and serving elementary ages $(45 \%)$.

\section{Instruments}

A survey was designed to examine the status of school psychology services in Portugal. In developing the survey, a range of sources were considered by the authors, including past questionnaires and research on school psychologists' functions and roles, feedback from individuals in the field, and web-based survey guidelines. The survey was piloted with ten school psychologists for navigation difficulties, question's clarity, and appropriateness. A testretest procedure was used to determine the stability of the survey overtime. The values of testretest correlation coefficients ranged from 0.72 to 1 for key variables in this study. Two senior researchers, members of the dissertation committee, and two members of the Directorate of 
General Education, related to the coordination of school psychology services, supervised the survey's development and implementation. On items regarding professional practice, participants were asked to estimate the average percentage of time spent, on annual basis, in a common set of school psychology roles and target audiences. Roles inquired included specialeducation-related activities, psychoeducational evaluation and counseling of regular education students, prevention and promotion, vocational guidance, school staff training and consultation, parents and family training and consultation, community liaison, and research. Target audiences comprised students, parents, teachers, school board members, school nonprofessional staff, and other specialists from school and the local community. The sum of all percentages had to be $100 \%$, a constraint that was enforced by the survey's software. A sevenpoint Likert scale, ranging from never (1) to always (7), was also given to participants to evaluate to what extent school community demanded for these professional practices. Finally, a rank-ordering question elicited participants' perceptions regarding ideal roles of school psychologists.

\section{Procedures}

The online survey was administered at the end of the 2012 school year. In the case of public schools, a saturation sample was carried out, while in the private sector, convenience sampling was used. Participants were contacted through an e-mail, addressed to the school's board of directors. Data collection was authorized by the Ministry of Education, which disseminated the surveys' e-mail invitation throughout the public school network, via regional structures. Private schools were located using national databases and contacted by the authors via e-mail. An e-mail hyperlink took participants to the study website. Prospective participants were presented with a brief explanation about the survey, the purpose and significance of the study, the criteria for being a respondent, and researcher's contacts and affiliation. The participants were assured that their participation was voluntary and that their responses would be kept confidential. Further details on the data collection procedures can be found in Mendes et al. (2014).

\section{Data analysis}

In order to identify distinct profiles of professional practice, cluster analysis was performed based on the percentage of time that practitioners reported spending with different target audiences. Since cluster analysis is sensitive to outliers, z-scores with an absolute value greater than 3.0 were deleted from the analyses $(n=31)$. Following Hair et al. (2009) recommendations, a two-stage clustering strategy was employed to select the cluster solution that best represent the data structure. A hierarchical cluster analysis was first carried out with exploratory purposes using the Ward's agglomeration method and the squared Euclidian distance. The decision regarding the optimal number of clusters was based on the computation of variance accounted by each cluster solution ( $R$-square). The amount of variance retained by each cluster solution was $44 \%$ (two clusters), $61 \%$ (three clusters), $65 \%$ (four clusters), $69 \%$ (five clusters), and $71 \%$ (six clusters). Grounded on a combination of statistical criteria (the largest $R$-square lip), parsimony, and interpretability, the three-cluster solution was chosen. A non-hierarchical procedure ( $K$-means) was then performed using the number of clusters and 
the cluster centroid provided by the hierarchical method as the seed points. To assess solution stability, subsequent cluster analyses were re-run by combining different linkage methods and measures of similarities. In all cases, the three clusters emerged as the optimal solution. Furthermore, the solution stability was examined by randomly dividing the study sample into two halves and applying the cluster analysis on each individually. The average Cohen's kappa value across the two subsamples provided substantial evidence for the stability of this threecluster solution $(K=.98)$.

Once the groups were established, the clusters were compared on external variables using variance analysis (ANOVAs). The external variables consisted on the distribution of time by professional practices, the demand of school community for each activity, perceptions regarding the ideal roles for school psychologists, and personal and professional background. First, exploratory procedures were employed to verify if the ANOVA assumptions were met. Although normality test suggested the violation of this assumption, the skewness and kurtosis of the distribution of each variable indicated no severe departures from normality. The Levene's test for the homogeneity of variance was non-significant in the majority of dependent variables tested. As suggested by Fife-Schaw (2006), whenever this violation was found, both parametric and their equivalent non-parametric tests were computed. Since the conclusions drawn from both set of tests were coincident in all cases, only the results of the parametric tests will be presented. When variance was heterogeneous, Welsh test and Games-Howell procedure were adopted given their robustness against this condition (Howell, 2008). Due the large number of analysis carried out, Bonferroni-adjusted alpha of 0.008 (0.05/6 tests) and 0.005 (0.05/9 tests) was used as a criterion of significance. Effect sizes from the ANOVAs were indicated by partial $\eta^{2}$ and evaluated using Cohen's criteria: small $=0.01$, medium $=0.06$, and large $=0.138$. All the analyses were carried out with the statistical package SPSS 22.0 for Windows.

\section{Results}

Table 1 displays the descriptive data and ANOVA results for the final cluster solution. Note that, in the case of cluster analysis, $F$-statistic only allows us to understand the relative contribution of each variable to the cluster solution, or the degree of separation of the clusters, and significant tests are meaningless.

Table 1 Description of the final cluster solution

\begin{tabular}{lllll}
\hline & $\begin{array}{l}\text { Cluster 1 } \\
(n=151) \\
M(S D)\end{array}$ & $\begin{array}{l}\text { Cluster 2 } \\
(n=214) \\
M(S D)\end{array}$ & $\begin{array}{l}\text { Cluster 3 } \\
(n=81) \\
M(S D)\end{array}$ & $F^{*}$ \\
\hline Students & $72.94(6.63)$ & $55.43(4.79)$ & $37.15(6.46)$ & 827.49 \\
Parents & $8.08(3.81)$ & $11.91(4.47)$ & $16.65(5.07)$ & 98.94 \\
Teachers & $8.66(3.70)$ & $14.58(5.21)$ & $19.28(5.07)$ & 170.16 \\
School board members & $3.91(2.44)$ & $6.23(3.79)$ & $8.65(4.31)$ & 54.73 \\
Non-professional staff & $1.52(1.68)$ & $2.74(1.39)$ & $4.65(2.82)$ & 47.69 \\
Other specialists & $4.89(3.72)$ & $9.10(5.43)$ & $13.61(6.88)$ & 77.02 \\
\hline
\end{tabular}

*For all $F$-values, $p<.001$ 
Based on the mean values of clustering variables, a descriptive name for each cluster was defined. The first cluster was labeled as "student-oriented," since individuals in this group reported spending the great majority of their time working with this population. The second cluster, comprised by practitioners that referred to almost equitably distributing their time between adults and students, was named "balanced." The third cluster, named "adult-oriented," was distinguished by high percentages of time devoted to adults. Time spent with students was the variable that best discriminated between the three clusters, followed by time spent with teachers (higher $F$-value, see Table 1).

Separate one-way ANOVAs were used to investigate differences across clusters in the amount of time spent in a set of common school psychologists' activities. For this analysis, a composite variable was created by summing the percentage of time spent in the provision of indirect services (i.e., training, consultation, community liaison, and research). This decision beyond theoretically grounded relates to the fact that respondents reported spending on average only 1 to $7 \%$ of their time in these activities. Exploratory analysis revealed that the $F$-test significance was not amended by this modification.

The average percent of time spent in each professional practice, by cluster, is presented in Table 2.

The results of a one-way ANOVA revealed significant differences across clusters in the amount of time spent in psychoeducational evaluation, counseling, vocational guidance, prevention and health promotion, vocational guidance, and indirect services. The effect size of the results ranged from small to moderate, with cluster membership accounting for 2 to $14 \%$ of the variance.

The post hoc comparisons using Scheffé and Games-Howell procedures indicated that, when compared to the other groups, practitioners in the cluster student-oriented reported to spend significantly more time assessing and counseling regular education students and significantly less time in indirect and preventive services. On the other hand, respondents in the cluster adult-oriented differ from the other groups for devoting significantly less time to vocational guidance.

To study the link between cluster membership and different patterns of professional activity, the level of demand of the school community for each professional practice was explored (Table 3).

Significant differences across clusters were found in the level of demand for activities such as student counseling, prevention and health promotion, vocational guidance, community liaison, parents and school staff training, and consultation. Although differences were found,

Table 2 Cluster means for percent of time spent in different professional practices

\begin{tabular}{|c|c|c|c|c|c|}
\hline & $\begin{array}{l}\text { Student-oriented } \\
(n=151)\end{array}$ & $\begin{array}{l}\text { Balanced } \\
(n=214)\end{array}$ & $\begin{array}{l}\text { Adult-oriented } \\
(n=81)\end{array}$ & & \\
\hline & $M(S D)$ & $M(S D)$ & $M(S D)$ & $F$ & $\eta^{2}$ \\
\hline Special education & $11.87(8.10)$ & $13.09(9.00)$ & $13.10(9.90)$ & 0.94 & \\
\hline Psychoeducational evaluation & $22.10(9.93)$ & $18.89(10.16)$ & $18.49(9.40)$ & $5.62 *$ & 0.02 \\
\hline Counseling students & $23.62(12.36)$ & $18.98(10.43)$ & $17.73(8.10)$ & $11.12 * *$ & 0.05 \\
\hline Prevention and promotion & $8.81(7.16)$ & $10.65(8.60)$ & $12.26(7.65)$ & $5.29 *$ & 0.02 \\
\hline Vocational guidance & $19.48(11.37)$ & $18.45(12.26)$ & $13.85(9.27)$ & $6.73 * *$ & 0.03 \\
\hline Indirect services & $14.10(8.22)$ & $19.93(9.57)$ & $24.56(10.84)$ & $35.71 * *$ & 0.14 \\
\hline
\end{tabular}

Significance at 0.008 level using a Bonferroni correction to prevent type I error

$* p<.01 ; * * p<.001$ 
Table 3 Level of demand of the school community for different professional practices by cluster

\begin{tabular}{|c|c|c|c|c|c|}
\hline & $\begin{array}{l}\text { Student-oriented } \\
(n=151)\end{array}$ & $\begin{array}{l}\text { Balanced } \\
(n=214)\end{array}$ & $\begin{array}{l}\text { Adult-oriented } \\
(n=81)\end{array}$ & & \\
\hline & $M(S D)$ & $M(S D)$ & $M(S D)$ & $F$ & $\eta^{2}$ \\
\hline Special education & $5.31(1.92)$ & $5.43(1.81)$ & $5.17(1.94)$ & 0.61 & \\
\hline Psychoeducational evaluation & $6.23(1.28)$ & $6.11(1.36)$ & $6.20(1.24)$ & 0.43 & \\
\hline Counseling students & $6.30(0.92)$ & $5.89(1.38)$ & $5.81(1.08)$ & $6.82 *$ & 0.03 \\
\hline Prevention and promotion & $2.93(1.39)$ & $3.42(1.57)$ & $3.45(1.55)$ & $5.42 *$ & 0.02 \\
\hline Vocational guidance & $6.21(1.28)$ & $6.00(1.46)$ & $5.15(2.08)$ & $13.07 * *$ & 0.06 \\
\hline School staff training/consultation & $2.63(1.15)$ & $3.30(1.40)$ & $3.50(1.62)$ & $14.00 * *$ & 0.06 \\
\hline Family training/consultation & $3.26(1.53)$ & $3.78(1.70)$ & $4.20(1.71)$ & $9.20 * *$ & 0.04 \\
\hline Community liaison & $3.20(1.36)$ & $3.94(1.56)$ & $4.11(1.63)$ & $14.08 * *$ & 0.06 \\
\hline Research & $1.52(1.13)$ & $1.67(1.08)$ & $1.70(1.05)$ & 1.16 & \\
\hline
\end{tabular}

The scale ranged from 1 (never) to 7 (always). Significance at 0.005 level using a Bonferroni correction to prevent type I error

$* p<.01 ; * * p<.001$

their effect size was very small, except in the case of vocational guidance where a moderate effect size was observed. Post hoc Scheffé and Games-Howell tests revealed that participants in the cluster student-oriented reported significantly higher demands for counseling services, and fewer demands to engage in activities such as parents and school staff training and consultation, community liaison, prevention, and health promotion. Post hoc comparisons also indicated that the cluster adult-oriented reported significantly fewer demands for vocational guidance.

An average ranking for each role was computed to determine which roles were conceived as the most and least ideal (Table 4). For this analysis, weights were applied in reverse order of the original rank and roles presenting the largest average rankings represent optimal roles. Univariate ANOVAs were then performed to investigate group differences.

As shown in Table 4, practitioners' perceptions regarding the most and least ideal roles of school psychologists are quite consistent across clusters. An analysis of the most optimal roles shows that, for all clusters, psychoeducational evaluation, student counseling, vocational guidance, prevention, and promotion were among the top four ranked choices, with psychoeducational evaluation systematically occupying the first position. Indirect services, such as training, consultation, and community liaison, were consistently identified across clusters as the least optimal roles, and respondents unanimously rated research as the least ideal role. Significant differences across groups were exclusively found in the average weight attributed to teachers and other school staff training and consultation, with participants from the clusters balanced and adult-oriented placing a greater value on these activities.

Further analyses were performed in order to explore group differences on personal, professional, and practice setting variables. The one-way ANOVA results showed no significant differences between clusters according to years of experience as a school psychologist $(F$ $(2,443)=0.48, p=.62)$, highest degree held $\left(\chi^{2}(2,446)=0.60, p=.74\right)$, and area of specialization within the psychology field prior entering the profession $\left(\chi^{2}(1,446)=3.94, p=.42\right)$. However, in terms of contextual variables, differences between groups were found on schoolpsychologist-to-student ratio $\left(F(2,443)=12.66, p<.001, \eta^{2}=0.05\right)$, ratio of schools per 
Table 4 Average ranking for the ideal roles of school psychologists by cluster

\begin{tabular}{|c|c|c|c|c|c|}
\hline & $\begin{array}{l}\text { Student-oriented } \\
(n=151)\end{array}$ & $\begin{array}{l}\text { Balanced } \\
(n=214)\end{array}$ & $\begin{array}{l}\text { Adult-oriented } \\
(n=81)\end{array}$ & & \\
\hline & $M(S D)$ & $M(S D)$ & $M(S D)$ & $F$ & $\eta^{2}$ \\
\hline Special education & $6.68(2.47)$ & $6.69(2.63)$ & $6.33(2.69)$ & 0.60 & \\
\hline Psychoeducational evaluation & $8.97(2.46)$ & $9.00(2.35)$ & $9.06(2.40)$ & 0.04 & \\
\hline Counseling students & $8.23(2.66)$ & $7.53(2.87)$ & $7.22(2.89)$ & 4.21 & \\
\hline Prevention and promotion & $7.69(1.81)$ & $7.62(2.13)$ & $7.75(1.85)$ & 0.14 & \\
\hline Vocational guidance & $8.13(2.09)$ & $7.95(2.33)$ & $7.35(2.41)$ & 3.25 & \\
\hline School staff training/consultation & $3.68(1.68)$ & $4.39(1.88)$ & $4.86(2.08)$ & $12.40^{*}$ & 0.06 \\
\hline Family training/consultation & $5.45(2.02)$ & $5.39(1.99)$ & $5.79(1.90)$ & 1.21 & \\
\hline Community liaison & $3.76(1.83)$ & $3.58(1.80)$ & $3.36(1.80)$ & 1.28 & \\
\hline Research & $2.05(1.78)$ & $1.83(1.52)$ & $1.67(1.55)$ & 1.65 & \\
\hline
\end{tabular}

Significance at 0.005 level using a Bonferroni correction to prevent type I error $* p<.001$

school psychologist $\left(F(2,443)=13.12, p<.001, \eta^{2}=0.06\right)$, and number of students' referrals per year $\left(F(2,443)=12.94, p<.001, \eta^{2}=0.06\right)$. A follow-up contrast showed that practitioners from the adult-oriented cluster worked on average with lower school-psychologist-tostudent ratios $(M=863.64, S D=592.61)$ in comparison with the student-oriented $(M=1315.11, S D=722.56)$ and balanced clusters $(M=1118.44, S D=629.93)$. On the other hand, practitioners from the student-oriented cluster reported to cover on average a higher number of school buildings geographically dispersed $(M=8.18, S D=8.15)$ by comparison to their colleagues $(M=5.10, S D=5.01 ; M=4.60, S D=4.25$, for balanced and adult-oriented clusters). Finally, practitioners from the adult-oriented cluster reported a lower average number of students' referrals per year $(M=60.49, S D=23.12)$ when compared to the student-oriented $(M=86.06, S D=40.63)$ and balanced clusters $(M=86.45, S D=46.71)$. These differences represented small to medium effect sizes, explaining 5 to $6 \%$ of the variance between clusters. No between-group differences were found in terms of school setting (i.e., rural, suburban, and urban; $\left.\chi^{2}(2,426)=2.635, p=.62\right)$ and type of educational establishment (i.e., elementary, secondary, or schools that combine elementary and secondary education; $\chi^{2}(2,446)=6.755$, $p=.14)$.

\section{Discussion}

Overall, the results of this study suggest that Portuguese school psychologists represent a heterogeneous population with respect to professional practices. Three profiles of school psychologists emerged from cluster analysis: a group highly oriented to work with students, a group that distributed time almost equitably between students and adults, and a group that concentrated their attention and professional expertise on adults. These clusters were labeled as studentoriented, balanced, and adult-oriented and represent respectively 34,48 , and $18 \%$ of the sample.

Despite that school psychologists in the student-oriented and balanced clusters reported to spend most of their time with students, a traditional child-centered practice was particularly evident in the first cluster. This cluster, when compared to the other groups, reported to spend 
significantly more time assessing and counseling students, and significantly less time providing indirect and preventive services. Conceived as an overly restrictive and reactive response to educational problems, this pattern of professional practice seems to portray what Gutkin and Conoley (1990) characterized as the school psychology paradox. The paradox is that school psychologists continue to work directly with children even though to serve children best and most effectively, they should, first and foremost, focus their professional skills on the adults who are in a position to influence the child and modify his/her environment.

This traditional model of service delivery, where interventions are primarily designed to address students' characteristics and intrapersonal attributes, has been broadly criticized for disregarding important factors to students' mental health, well-being, and success in school and in life (Engelbrecht, 2004; Farrell, 2010; Gutkin \& Conoley, 1990; Gutkin \& Song, 2013; Gutkin, 2012). It has also long been associated with an inefficient use of school psychologists' time for responding to the needs of students on a case-by-case basis (Merrell et al., 2012), thus producing quite a small impact on the school population (Fagan \& Wise, 2007). Ultimately, it has been recognized as unsustainable considering that the number of students with learning and mental health problems is growing without a corresponding increase in schools and community resources (Doll \& Cummings, 2007; Merrell et al., 2012; Meyers \& Swerdlik, 2003). Nonetheless, a referral-based and individually focused model of practice was observed in about a third of Portuguese practitioners.

The increasing concern about the continuing failure of this approach to address what some call a "mental health and education pandemic" (Gutkin, 2012, p. 6) has led to repeated calls for a paradigm shift where population-focused, prevention-oriented, and indirect models are in the center of school psychologist intervention (e.g., Albee, 1999; Cummings et al., 2004; Doll \& Cummings, 2007; Engelbrecht, 2004; Farrell, 2006, 2010; Gutkin \& Conoley, 1990; Gutkin, 2012; Nastasi, 2000, 2004; Strein et al., 2003; Ysseldyke et al., 2006). Notwithstanding, research shows that worldwide school psychologists still struggle achieving this in practice, although they often wish to do so.

Portuguese school psychologists are not an exception in this regard. As the results of this study revealed, regardless of the differences found across clusters, practitioners repeatedly reported spending the least amount of time in prevention and promotion activities. On the other hand, school psychologists who reported primarily working directly with adults encompassed the smallest cluster. Even so, this group of practitioners reported spending no more than a quarter of their time in indirect services, which in this study corresponded to the total time spent in school staff training and consultation, family training and consultation, community liaison, and research.

The emphasis on primary and secondary prevention stems from the awareness that there will never be sufficient resources to provide direct services to all individuals in need (Albee, 1968). On the other hand, it is recognized that to invest exclusively in remediation services is neither effective nor economically sustainable (Gutkin, 2012; Merrell et al., 2012). As Albee (1999) noted, no mass disorder has ever been eliminated by treating solely the affected individuals, especially one at the time. In contrast, there is a long-standing acceptance of prevention and indirect services as core components of the profession and that through these services school psychologists should be able to increase their impact in schools.

Curiously, the results of this study revealed a great deal of consistency between school psychologists' patterns of professional practice and school community demands. The cluster that revealed a traditional child-centered practice, when compared to the other groups, reported significantly higher levels of demand to offer counseling to students and lower levels of demand for prevention-oriented and indirect services. Additionally, the cluster adult-oriented, which 
distinguished itself from the other groups for devoting significantly less time to vocational guidance, also reported significantly lower levels of demand for this activity. Furthermore, regardless of the statistical significance of the results presented, a general tendency was observed where the most time-consuming activities were in fact the most requested services, and vice versa. The most demanded roles to school psychologists in all clusters were specialeducation-related services, psychoeducational evaluation, counseling, and vocational guidance.

These findings are consistent with previous research that acknowledges the attitudes and perceptions of the school community toward the profession as one of the major factors affecting school psychologists' functions and roles. Prior studies have generally found that teachers and school administrators tend to identify assessment, diagnosis, and special education eligibility as the primary duties of school psychologists (e.g., Farrell et al., 2005; Gilman \& Gabriel, 2004; Watkins et al., 2001). Some of these studies also suggested that other education professionals desire for school psychologists to expand the range of service provided (e.g., Anthun, 1999; Farrell et al., 2005; Watkins et al., 2001). However, research reveals that if having to choose, namely, due to the lack of human and financial resources, the school personnel tend to give priority to traditional roles and child-centered services (Magi \& Kikas, 2009).

These results are also in line with prior literature that describes that the schools themselves have a traditional view of school psychology services. School psychologists are usually expected to work primarily with students experiencing any sort of difficulties, perceived by the school community as direct services providers, and as experts in the diagnosis and treatment of learning and mental health problems (Gilman \& Medway, 2007; Kikas, 1999; Sheridan \& Gutkin, 2000; Williams \& Greenleaf, 2012). Within this scenario, practitioners might find it difficult to step away from traditional roles and service delivery models, which have historically dominated the profession and have now become institutionalized and the expected services' modus operandi. According to Engelbrecht (2004), by maintaining traditional practices, school psychologists have also implicitly or explicitly subscribed these beliefs toward the profession.

When examining school psychologists' opinions regarding the ideal roles of the profession, a relatively high consistency across clusters was observed in the rank order of different roles. The one exception was school staff training and consultation, which was significantly more valued by the balanced and adult-oriented clusters. Overall, independently of the cluster membership, practitioners tended to favor direct over indirect services and remediation over prevention. This is by no means to claim that Portuguese practitioners devalue prevention and health promotion, but rather that practitioners across clusters do not perceive prevention and promotion as the first-line strategies to address students' problems, favoring traditional direct services, such as assessment, counseling, special education placements, and referrals.

Based on the data presented, it seems that practitioners' perception of ideal roles has a less explanatory power than the school community demands when it comes to understand school psychologists' practices. In fact, school psychologists collectively endorsed the activities most demanded by schools as the most optimal roles for school psychologists, and vice versa. However, practitioners' patterns of response suggests that school psychologists tend to place greater value on prevention and promotion, as well as in family training and consultation, than what schools' required from them.

As in most countries inquired with ISPS (Jimerson et al. 2007, 2008a, b, 2009, 2010), Portuguese practitioners frequently ranked assessment, counseling, and prevention among the top four ideal roles of school psychologists. On the other hand, divergent results were found in the rank order assigned to school staff training and consultation, which were often more valued internationally. Along with the aforementioned activities, practitioners ranked 
vocational guidance among the top four preferred roles. This result is not surprising given that vocational guidance is recognized as one of the core components of the profession, being linked to the early entrance of psychologists in Portuguese schools (Mendes et al., 2014).

This study identified three distinct profiles of school psychologists, albeit when examining group differences on personal and background variables, such as preservice training and professional experience, no significant differences were found across clusters. Prior studies have found contradictory findings on the influence of these factors on school psychologists' functions and roles, with most failing to support this relationship, as it was observed in this study (e.g., Brown et al., 1998; Costenbader et al., 1992; Hughes \& Clark, 1981). In contrast, differences across clusters were found in what regards to school-psychologist-to-student ratio, school psychologist-to-school ratio, and number of referrals per year.

One of the most cited concerns among school psychologists is the effect of the number of students per school psychologist on professional practices. Higher ratios have been associated with more time spent in traditional and less desirable roles, such as assessment and special education, with this time preventing school psychologists from engaging in a broad range of services (Curtis et al., 2002; Hosp \& Reschly, 2002). Consistent with these reports, practitioners with lower school-psychologists-to-student ratios and more manageable students' referrals (i.e., adult-oriented cluster) reported a higher involvement in indirect and prevention-oriented services. In turn, as Braden et al. (2001) asserts, serving large geographically disperse school populations showed to foster a more reactive than proactive approach (i.e., student-oriented cluster).

The results of this study not only support the assumption that a high ratio "contributes to a focus on discrete problems and services that impact relatively small numbers of students" (Meyers \& Swerdlik, 2003, p. 258). They also follow logic, as the more students in a school setting, the larger the proportion of children with any sort of difficulties or problems, and the higher the probability of students being referred to services. Preventive and indirect services have been recognized as the best and maybe the only way to reach larger numbers of children in schools where ratios are high. However, as the current data suggest, school psychologists who work in settings with high ratios, high caseloads, and high pressure to provide direct and deficit-focus services may be reluctant or unable to move away from this service delivery model. As Farrell (2010) advocates, when a service is in high demand but with short supply, there is a tendency for practitioners to comply with the expected roles.

\section{Limitations and future research}

Limitations inherent to the use of saturation and convenience sampling methods, as well as self-report and retrospective data, require caution when interpreting these results. Both methodological approaches limit the external validity and reliability of research findings. Furthermore, while some of the data collected are likely to be accurate, the estimations of time percentages are susceptible to being overestimated or underestimated. Despite all the efforts to make a distinction fairly between school psychologists' roles, one must recognize that some overlaps between categories might exist, making it difficult for practitioners to estimate time percentages. In addition, although cluster analysis is a valuable method to identify patterns within a dataset, this method is subject to countless decisions by the researcher, which potentially influence results. Finally, this study examined the factors influencing school psychologists' patterns of professional practice, through using a limited 
set of personal and contextual variables to contrast clusters. Moreover, the small to moderate effect sizes found for some of the outcomes raise questions about the practical significance of these variables on school psychologists' functions and roles.

Therefore, several suggestions for future research are noted. First, future research should attempt to verify and validate this cluster solution. To that end, future surveys need to inquire school psychologists about the time spent with different target audiences. Future studies might conversely choose to cluster school psychologists based on the amount of time spent in different functions and roles. One of the advantages of this approach is that it allows the use of databases from previous survey to perform such analysis. One of the disadvantages relies on the inconsistent categorization of school psychologists' practices across surveys, which limit the comparison of research findings. Second, understanding the factors that contribute to different patterns of service delivery continues to be a critical area of research. The results of these studies have the potential to support the development of evidence-based strategies and tailored action plans directed to target distinct profiles of practitioners and the variables associated. Lastly, qualitative studies could be used to explore these clusters further. Focus groups and interviews can be useful to obtain a more in-depth understanding of how practitioners in different profiles perceive their role, different models of service delivery, current facilitators and barriers to practices, and practitioners' attitudes toward role change. Case studies based on practitioners presenting more effective patterns of service delivery may help to operationalize, share, and discuss examples of good practices in the field.

\section{Practical implications}

School psychologists are not a homogenous population in terms of professional practices. Despite being useful for trend analysis, planning, and generating hypotheses, descriptive studies have the potential to trigger negative feedbacks from those professionals who might feel misrepresented in the outcomes and conclusions derived from central tendency measures. Profiling school psychologists by distinct patterns of activity not only allows for a more comprehensive picture of the profession but also enhances the likelihood of practitioners to identify themselves with research findings. This is a relevant issue when one of the major goals of the field is to connect practitioners and researchers and to ensure that research informs practice.

This also suggests that when communicating with school psychologists about services delivered, a uniform speech should be avoided. Generic statements and recommendations regarding the profession might be insufficient to promote self-reflection and role change, especially in those practitioners more resistant to change. Tailoring and targeting communication strategies, suited to distinct profiles of school psychologists, may be more effective to reach practitioners, increase awareness of best practices, and influence attitudes and behaviors toward change.

This does not exclude, however, the need to address a common and consistent message to practicing school psychologists. The publication of professional standards and guidelines is one of the best ways to achieve this goal. In Portugal, guidelines for psychological practice in schools are currently under development. Based on the results presented, those responsible for developing such a framework may consider the explicit endorsement of prevention, early intervention, and population-based approaches as key strategies in service delivery. Moreover, it should recognize indirect services as core components of the profession, encouraging practitioners to become more involved in consultation, in-service training, and collaboration. 
Such explicit statements seem particularly important considering the high number of practitioners that exhibit a student-centered and remedial pattern of professional activity.

Of course, this framework will be of little use if school psychologists themselves do not recognize these roles as cornerstones of best practices in school psychology. The results of this study suggest that, independently of the cluster membership, most participants still perceive traditional roles as the most ideal roles for school psychologists. Professional development activities can certainly play a key role in helping change perceptions held by many practitioners. As practitioners present different patterns of professional activity, one can hypothesize that they also present different levels of knowledge and skills in different domains. Ideally, the planning of professional developmental programs will consider this variability.

The implementation and sustaining of population-focused and indirect practices require a shared commitment between school psychologists, parents, school staff, and other relevant stakeholders. The results of this study support the assumption that school communities might have an import influence on school psychologists' role. They suggest that as school communities place higher demands for reactive and direct services, school psychologists will exhibit a greater tendency to engage in student-centered practice. Therefore, educating parents, school staff, and other stakeholders about the broad range of functions that school psychologists can perform and the benefits and constraints associated with different models of service delivery may have a positive effect on the profession. By understanding the cost-benefits associated with preventive, population-based, and indirect approaches, school communities may be more willing to value and demand these kind of services.

The increase of school-psychologist-to-student ratio has been pointed as an opportunity for school psychologists to re-conceptualize their role (e.g., Curtis et al. 2004). However, the results of this study suggest that ratios seem to be more a barrier than a stimulus to change, being associated with student-centered practices. An immediate and oversimplistic implication of this finding would be to increase the efforts to recruit and retain more school psychologists. However, such measures alone have been acknowledged as insufficient (Cummings et al., 2004), suggesting that the recruitment of more professionals needs to be accompanied by a comprehensive range of initiatives to effectively support school role change.

Finally, despite going beyond the scope of this study, it should be also noted that educational policies have certainly played an important role on the maintenance of studentcentered practices. Portuguese law requires school psychologists to conclude initial assessments and determination of special education eligibility in a short period of time. Practitioners are also mandated to assess students at risk for vocational education. Moreover, they hold responsibilities in the evaluation and intervention with regular education students facing any sort of social, emotional, learning, or mental health problems. Given the unfavorable ratios encountered in most school settings, it seems easy for school psychologists to be trapped in assessment duties, report writing, and remediation activities. Consequently, school psychologists need to keep track and be more active at the political level in order to influence relevant laws and policies that might affect the profession.

\section{Final considerations}

School psychology services do not exist within a vacuum. Service delivery is a product of the combination of microsystemic, mesosystemic, and macrosystemic variables; thus, variability is expected. The range of factors that influence school psychologists' roles and the complexity of 
interactions among them make this a challenging area of research. More research is needed to understand why school psychologists engage in the practice they do. The results of these studies can led to differentiated and targeted policies, advocacy efforts, and strategies to support and communicate with different practitioners to advance their practices.

\section{References}

Albee, G. W. (1968). Conceptual models and manpower requirements in psychology. The American Psychologist, 23(5), 317-320. doi:10.1037/h0026125.

Albee, G. W. (1999). Prevention, not treatment, is the only hope. Counselling Psychology Quarterly, 12(2), 133146. doi:10.1080/09515079908254084.

Anthun, R. (1999). Quality and improvement potential in school psychology services. School Psychology International, 20(2), 163-175. doi:10.1177/0143034399202001.

Bartolo, P. A. (2010). Why school psychology for diversity? School Psychology International, 31(6), 567-580. doi: $10.1177 / 0143034310386532$.

Benson, A. J., \& Hughes, J. (1985). Perceptions of role definition processes in school psychology: a national survey. School Psycology Review, 14(1), 64-74.

Braden, J. S., DiMarino-Linnen, E., \& Good, T. L. (2001). Schools, society, and school psychologists history and future directions. Journal of School Psychology, 39(2), 203-219. doi:10.1016/S0022-4405(01)00056-5.

Bramlett, R. K., Murphy, J. J., Johnson, J., Wallingsford, L., \& Hall, J. D. (2002). Contemporary practices in school psychology: a national survey of roles and referral problems. Psychology in the Schools, 39(3), 327335. doi:10.1002/pits.10022.

Brown, M. B., Swigart, M. L., Bolen, L. M., Hall, C. W., \& Webster, R. T. (1998). Doctoral and nondoctoral practicing school psychologists: are there differences? Psychology in the Schools, 35(4), 347-354. doi:10. 1002/(SICI)1520-6807(199810)35:4<347::AID-PITS5>3.0.CO;2-9.

Burns, M. K. (2011). School psychology research: combining ecological theory and prevention science. School Psycology Review, 40(1), 132-139.

Castillo, J. M., Curtis, M. J., \& Gelley, C. (2012). School psychology 2010: school psychologists' professional practices and implications for the field. Communiqué, 40(8), 4-6.

Christner, R. W., Mennuti, R. B., Heim, M., Gipe, K., \& Rubenstein, J. S. (2011). Facilitating mental health services in schools: universal, selected, and targeted interventions. In T. M. Lionetti, E. P. Snyder, \& R. W. Christner (Eds.), A practical guide to building professional competencies in school psychology (pp. 175192). New York, NY: Springer.

Costenbader, V., Swartz, J., \& Petrix, L. (1992). Consultation in the schools: the relationship between preservice training, perception of consultative skills, and actual time spent in consultation. School Psycology Review, 21(1), 95-108.

Cummings, J. A., Harrison, P. L., Dawson, M. M., Short, R. J., Gorin, S., \& Palomares, R. S. (2004). The 2002 conference on the future of school psychology: implications for consultation, intervention, and prevention services. Journal of Educational and Psychological Consultation, 15(3-4), 239-256. doi:10.1080/ 10474412.2004.9669516.

Curtis, M. J., Grier, J. E. C., \& Hunley, S. A. (2004). The changing face of school psychology: trends in data and projections for the future. School Psycology Review, 33(1), 49-66.

Curtis, M. J., Hunley, S. A., Grier, J. E. C. (2002). Relationships among the professional practices and demographic characteristics of school psychologists. School Psychology Review, 31(1), 30-42.

Curtis, M. J., Lopez, A. D., Castillo, J. M., Batsche, G. M., Minch, D., \& Smith, J. C. (2008). The status of school psychology: demographic characteristics, employment conditions, professional practices, and continuing professional development. Communiqué, 36(5), 27-29.

Doll, B., \& Cummings, J. A. (2007). Why population-based services are essential for school mental health, and how to make them happen in your school. In B. Doll \& J. A. Cummings (Eds.), Transforming school mental health services: population-based approaches to promoting the competency and wellness of children (pp. 122). Thousand Oaks, CA: Corwin.

Ehrhardt-Padgett, G. N., Kitson, J., \& Meyers, J. (2004). Awakening to a new dawn: perspectives of the future of school psychology. School Psychology Quarterly, 33(1), 105-114.

Engelbrecht, P. (2004). Changing roles for educational psychologists within inclusive education in South Africa. School Psychology International, 25(1), 20-29. doi:10.1177/0143034304041501.

Fagan, T. K., \& Wise, P. S. (2007). School psychology: past, present and future (3rd ed.). Bethesda, MD: National Association of School Psychologists. 
Farrell, P. T. (2006). Developing inclusive practices among educational psychologists: problems and possibilities. European Journal of Psychology of Education, 21(3), 293-304. doi:10.1007/BF03173417.

Farrell, P. T. (2010). School psychology: learning lessons from history and moving forward. School Psychology International, 31(6), 581-598. doi:10.1177/0143034310386533.

Farrell, P. T., Jimerson, S. R., Kalambouka, A., \& Benoit, J. (2005). Teachers' perceptions of school psychologists in different countries. School Psychology International, 26(5), 525-544. doi:10.1177/ 0143034305060787 .

Fife-Schaw, C. (2006). Levels of measurement. In G. M. Breakwell, S. Hammond, C. Fife-Schaw, \& J. A. Smith (Eds.), Research methods in psychology (pp. 50-63). London: SAGE Publications, Inc.

Gilman, R., \& Gabriel, S. (2004). Perceptions of school psychological services by education professionals: results from a multi-state survey pilot study. School Psycology Review, 33(2), 271-286.

Gilman, R., \& Medway, F. J. (2007). Teachers' perceptions of school psychology: a comparison of regular and special education teacher ratings. School Psychology Quarterly, 22(2), 145-161. doi:10.1037/1045-3830.22.2.145.

Gutkin, T. B. (2012). Ecological psychology: replacing the medical model paradigm for school-based psychological and psychoeducational services. Journal of Educational and Psychological Consultation, 22(1-2), 1-20. doi:10.1080/10474412.2011.649652.

Gutkin, T. B., \& Conoley, J. C. (1990). Reconceptualising school psychology from a service delivery perspective: implications for practice, training, and research. Journal of School Psychology, 28(3), 203-223. doi:10.1016/0022-4405(90)90012-V.

Gutkin, T. B., \& Song, S. Y. (2013). Social justice in school psychology: a historical perspective. In D. Shriberg, S. Y. Song, A. H. Miranda, \& K. M. Radliff (Eds.), School psychology and social justice: conceptual foundations and tools for practice (pp. 15-28). New York, NY: Routledge/Taylor \& Francis.

Hair, J. F. J., Anderson, R. E., Atham, R. L., \& Black, W. (2009). Multivariate data analysis (7th ed.). Upper Saddle River, NJ: Prentice Hall.

Hosp, J. L., \& Reschly, D. J. (2002). Regional differences in school psychology practice. School Psycology Review, 31(1), 11-29.

Howell, D. (2008). Best practices in Anova. In J. W. Osborne (Ed.), Best practices in quantitative methods (pp. 341-357). Thousand Oaks, CA: SAGE Publications, Inc.

Hughes, J. N., \& Clark, R. D. (1981). Differences between urban and rural school psychology: training implications. Psychology in the Schools, 18(2), 191-196. doi:10.1002/1520-6807(198104)18:2<191::AIDPITS2310180214>3.0.CO;2-W.

Jimerson, S. R., Alghorani, M. A., Darweish, A. H., Abdelaziz, M., \& The ISPA Research Committee (2010). School psychology in Egypt: results of the 2008 international school psychology survey. School Psychology International, 31(3), 219-228. doi:10.1177/0143034310366413.

Jimerson, S. R., Annan, J., Skokut, M., Renshaw, T. L., \& The ISPA Research Committee (2009). Educational psychology in New Zealand: results of the 2006 international school psychology survey. School Psychology International, 30(5), 443-455. doi:10.1177/0143034309341617.

Jimerson, S. R., Graydon, K., Farrell, P. T., Kikas, E., Hatzichristou, C., Boce, E., \& The ISPA Research Committee (2004). The international school psychology survey: development and data from Albania, Cyprus, Estonia, Greece and Northern England. School Psychology International, 25(3), 259-286. doi:10. 1177/0143034304046901.

Jimerson, S. R., Oakland, T. D., \& Farrell, P. T. (2007). The international school psychology survey: insights from school psychologists around the world. In The handbook of international school psychology (pp. 481501). Thousand Oaks, CA: SAGE Publications, Inc.. doi:10.4135/9781412976138.

Jimerson, S. R., Graydon, K., Skokut, M., Alghorani, M. A., Kanjaradze, A., Forster, J., \& The ISPA Research Committee. (2008a). The international school psychology survey: data from Georgia, Switzerland and the United Arab Emirates. School Psychology International, 29(1), 5-28. doi:10.1177/0143034307088501.

Jimerson, S. R., Skokut, M., Cardenas, S., Malone, H., \& Stewart, K. (2008b). Where in the world is school psychology?: examining evidence of school psychology around the globe. School Psychology International, 29(2), 131-144. doi:10.1177/0143034308090056.

Kikas, E. (1999). School psychology in Estonia. School Psychology International, 20(4), 352-364.

Lacayo, N., Sherwood, G., \& Morris, J. (1981). Daily activities of school psychologists: a national survey. Psychology in the Schools, 18(2), 184-190. doi:10.1002/1520-6807(198104)18:2<184::AIDPITS2310180213>3.0.CO;2-R.

Magi, K., \& Kikas, E. (2009). School psychologists' role in school: expectations of school principals on the work of school psychologists. School Psychology International, 30(4), 331-346. doi:10.1177/ 0143034309106943.

Mendes, S. A., Abreu-Lima, I., Almeida, L. S., \& Simeonsson, R. J. (2014). School psychology in Portugal: practitioners' characteristics and practices. International Journal of School \& Educational Psychology, 2(2), 115-125. doi:10.1080/21683603.2013.863171. 
Mendes, S. A., Nascimento, I. M. G., Abreu-Lima, I. M. P., Almeida, L. S. (2015). A study of the ethical dilemmas experienced by school psychologists in Portugal. Ethics and Behavior, 1-20. doi:10.1080/ 10508422.2015.1029047

Merrell, K. W., Ruth, A. E., \& Peacock, G. G. (2012). School psychology for the 21st century: foundations and practices. Journal of School Psychology (2nd ed.). New York, NY: The Guilford Press.

Meyers, A. B., \& Swerdlik, M. E. (2003). School-based health centers: opportunities and challenges for school psychologists. Psychology in the Schools, 40(3), 253-264. doi:10.1002/pits.10085.

Murray, B. A. (1996). The principal and the school psychologist: partners for students. NASSP Bulletin, 80(580), 95-99. doi:10.1177/019263659608058012.

Nastasi, B. K. (2000). School psychologists as health-care providers in the 21st century: conceptual framework, professional identity, and professional practice. School Psychology Review, 29(4), 540-554.

Nastasi, B. K. (2004). Meeting the challenges of the future: integrating public health and public education for mental health promotion. Journal of Educational and Psychological Consultation, 15(3), 295-312. doi:10. 1207/s1532768xjepc153\&4_6.

National Association of School Psychologists. (2010). Model for comprehensive and integrated school psychological services. Bethesda, MD: National Association of School Psychologists.

Oakland, T. D., \& Cunningham, J. L. (1992). A survey of school psychology in developed and developing countries. School Psychology International, 13(2), 99-129. doi:10.1177/0143034392132001.

Reschly, D. J. (2004). Paradigm shift, outcomes criteria, and behavioral interventions: foundations for the future of school psychology. School Psychology Review, 33(3), 408-416.

Reschly, D. J., \& Wilson, M. S. (1995). School psychology practitioners and faculty: 1986 to 1991-92 trends in demographics, roles, satisfaction, and system reform. School Psycology Review, 24(1), 62-80.

Sheridan, S. M., \& Gutkin, T. B. (2000). The ecology of school psychology: examining and changing our paradigm for the 21st century. School Psycology Review, 29, 485-502.

Smith, D. K. (1984). Practicing school psychologists: their characteristics, activities, and populations served. Professional Psychology: Research and Practice, 15(6), 798-810. doi:10.1037//0735-7028.15.6.798.

Stinnett, T. A., Havey, J. M., \& Oehler-Stinnett, J. (1994). Current test usage by practicing school psychologists: a national survey. Journal of Psychoeducational Assessment, 12(4), 331-350. doi:10.1177/ 073428299401200403.

Strein, W., Hoagwood, K., \& Cohn, A. (2003). School psychology: a public health perspective I. Prevention, populations, and systems change. Journal of School Psychology, 41, 23-38.

Watkins, M. W., Crosby, E. G., \& Pearson, J. L. (2001). Role of the school psychologist: perceptions of school staff. School Psychology International, 22(1), 64-73. doi:10.1177/01430343010221005.

Williams, J. M., \& Greenleaf, A. T. (2012). Ecological psychology: potential contributions to social justice and advocacy in school settings. Journal of Educational and Psychological Consultation, 22(1-2), 141-157. doi:10.1080/10474412.2011.649653.

Ysseldyke, J. E., Burns, M. K., Dawson, P., Kelley, B., Morrison, D., Ortiz, S., \& Telzrow, C. (2006). School psychology: a blueprint for training in practice III. Bethesda, MD: National Association of School Psychologists.

Sofia A. Mendes, Faculty of Psychology and Educational Sciences, University of Porto, Centre of Psychology;

Jon Lasser, State Texas University, Department of Counseling, Leadership, Adult Education and School Psychology;

Isabel M. P. Abreu-Lima, Faculty of Psychology and Educational Sciences, University of Porto, Centre of Psychology;

Leandro S. Almeida, Department of Educational Psychology and Special Education, University of Minho; Jon Lasser, State Texas University, Department of Counseling, Leadership, Adult Education and School Psychology.

This research was financially sponsored by the Portuguese Foundation for Science and Technology (Doctoral grant, SFRH/BD/78646/2011). The authors would like to thank all school psychologists who participated in this study and to the Directorate-General of Education for supporting data collection.

Correspondence concerning this paper should be addressed to Sofia A. Mendes, Faculdade de Psicologia e Ciências de Educação, Rua Alfredo Allen, Sala FPCE136, 4200-135, Porto, Portugal, email: sofia.a.mendes@gmail.com. 
Most relevant publications in the field of Psychology of Education:

Sofia A. Mendes, MS.

Mendes, S. A., Abreu-Lima, I. M. P., Almeida, L. S., Simeonsson, R. J. (2014). School psychology in Portugal: practitioners' characteristics and practices. International Journal of School \& Educational Psychology, 2(2), 115-125. doi:10.1080/21683603.2013.863171.

Mendes, S. A., Nascimento, I. M. G., Abreu-Lima, I. M. P., Almeida, L. S. (2015). A study of the ethical dilemmas experienced by school psychologists in Portugal. Ethics and Behavior, 1-20. doi:10.1080/10508422.2015.1029047.

Mendes, S. A., Abreu-lima, I. M. P., Almeida, L. S. (2015). Psicólogos escolares em Portugal: perfil e necessidades de formação [School psychologists in Portugal: training profile and educational needs]. Estudos de Psicologia - Campinas, 32(3), 405-416. doi: 10.1590/0103-166X2015000300006.

Jon Lasser, PhD.

Lasser, J., Dark, L., Beam, K., Morris, M., Shatila, A. (in press). The multicultural transformation of a school psychology course: process and outcomes. Trainers' Forum.

Vega, D., Lasser, J., Plotts, C. (2015). Global migration: the need for culturally competent school psychol ogists. School Psychology International, 36, 358-374. doi: 10.1177/0143034315587011.

Klose, L.M., \& Lasser, J. (2014). Best practices in the application of professional ethics. In A. Thomas \& P. Harrison (Eds.). Best practices in school psychology VI (pp. 449-458). Bethesda, MD: National Association of School Psychologists.

Jantz, P. B., Vega, D., Klose, L.M., Lasser, J. (2014). Field-based practicum experiences in specialist-level school psychology programs: implications for graduate preparation. Trainers' Forum, 33(1), 38-47.

Plotts, C., \& Lasser, J. (2013). The school psychologist as counselor: a practitioner's handbook. Bethesda, MD: National Association of School Psychologists.

Isabel M. P. Abreu-Lima, PhD.

Abreu-Lima, I. M. P., Leal, T. B., Cadima, J., Gamelas, A. M., (2013). Predicting child outcomes from preschool quality in Portugal. European Journal of Psychology of Education, 28(2), 399-420. doi:10.1007/s10212-012-0120-y.

Almeida A., Abreu-Lima, I. M. P., Orlanda, C., Gaspar, M.F., Brandão, T., Alarcão, M., Santos, M. R., Machado, J. M. (2012). Parent education interventions: results from a national study in Portugal. European Journal of Developmental Psychology, 9(1), 135-149. doi: 10.1080/17405629.2011.647865.

Abreu-Lima, I. M. P. (2009). Quality of home environment and development of children: a study using "Home Inventory". Psicologia, 2, 115-128.

Leandro S. Almeida, PhD.

Soares, D. S., Lemos, G. C., Primi, R., Almeida, L. S. (2015). The relationship between intelligence and academic achievement throughout middle school: the role of students' prior academic performance. Learning and Individual Differences, 41, 73-78. doi:10.1016/j.lindif.2015.02.005.

Monteiro, S., Almeida, L. S., Vasconcelos, R. M., Cruz, J. F. A. (2014). Be(com)ing an excellent student: a qualitative study with engineering undergraduates. High Ability Studies, 2(25), 169-186. doi:10.1080/13598139.2014.966066.

Lemos, G. C., Abad, F. J., Almeida, L. S., Colom, R. (2013). Sex differences on g and non-g intellectual performance reveal potential sources of STEM discrepancies. Intelligence, 41(1), 11-18. doi:10.1016/j.intell.2012.10.009.

Butler, H. A., Dwyer, C. P., Hogan, M. J., Franco, A., Rivas, S. F., Saiz, C., Almeida, L. S. (2012). The Halpern Critical Thinking Assessment and real-world outcomes: cross-national applications. Thinking Skills and Creativity, 7(2), 112-121. doi:10.1016/j.tsc.2012.04.001.

Ferrando, M., Prieto, M. D., Almeida, L. S., Ferrándiz, C., Bermejo, R., López-Pina, J. A., Hernández, D., Sáinz, M., Fernández, M.C. (2011). Trait emotional intelligence and academic performance: controlling for the effects of IQ, personality, and self-concept. Journal of Psychoeducational Assessment, 29(2), 150-159. doi: $10.1177 / 0734282910374707$.

Caires, S., Almeida, L. S., Martins, C. (2010). The socioemotional experiences of student teachers during practicum: a case of reality shock?. The Journal of Educational Research, 103(1), 17-27. doi: 10.1080/ 00220670903228611 . 